\title{
An investigation into environmental waste enforcement in Ireland
}

\author{
Alvaro Palomo-Navarro*, Aidan McDermott, John Dooley and Ronan Farrell \\ Callan Institute for Applied ICT, National University of Ireland, Maynooth, Ireland
}

(Received 25 June 2013; accepted 20 December 2013)

\begin{abstract}
Despite a number of campaigns conducted in Ireland to increase awareness about appropriate waste management, waste enforcement is still a significant issue. Decisions such as the privatisation of waste collection services and the introduction of new waste charges have contributed to some of the classic waste enforcement issues, like illegal dumping. In addition, the current economic recession affects the resources that local authorities have available to implement enforcement actions. In order to analyse the current situation of waste enforcement in Ireland, a survey was carried out amongst the 34 environmental departments within the Irish local authorities. This paper presents the survey findings. From the results, the principal current waste enforcement issues are extracted and compared with previous studies in the field. In addition, an analysis of the resources employed with regard to technology, personnel, legal prosecutions and best practices is also performed. The technologies and practices used are evaluated for efficiency at reducing the main illegal actions, such as illegal dumping, and compared to international best practices. Finally, the actions carried out by the local authorities in terms of public awareness and environmental education are reviewed.
\end{abstract}

Keywords: waste; enforcement; prosecution; best practice; technology; Irish local authorities

\section{Introduction}

We live in a society where the endless desire for the new has led to a significant decrease in the useful lifespan of the products we consume (Gregson et al. 2007). At the end of their useful existence, also known as end-of-life, these products are disposed of and become what is known as waste. Waste disposal does not mean that the products cease to exist in a material way, instead, they are relocated to other places in order to undergo different rematerialisation processes (Davies 2012). Reuse, recycling and recovery are some of the rematerialisation processes which seek to provide a sustainable alternative to the classic landfill disposal of waste (DECLG 2012).

For the European Union (EU) member states, the European Commission (EC) establishes and regulates legislation in relation to environmental policies. The Waste Framework Directive (EC 2008) defines the obligations of all EU members to develop national waste management plans and waste prevention plans. In addition, it reinforces the polluter-pays principle whereby the producer or holder of waste is responsible for the cost of its disposal in a manner that guarantees a high level of protection of the environment and human health. The correct implementation of the polluter-pays principle

\footnotetext{
*Corresponding author. Email: apalomo@eeng.nuim.ie 
is monitored and reinforced by the EC and the Court of Justice at the member state national level, and by the environment regulators of each member state at a regional level.

In Ireland, the Environmental Protection Agency (EPA) and the local authorities are responsible for the national and local environmental law enforcement. The environmental enforcement activities of the EPA focus on four different areas: waste, water, air and noise, and large industrial activities (EPA 2009). The main objectives of these actions are to improve compliance with environmental legislation, to raise awareness about the importance of environmental protection, to achieve more consistent enforcement by local authorities, to promote the polluter-pays principle and to communicate the enforcement actions to all stakeholders including the general public. Of the four environmental enforcement areas, waste enforcement shows the highest number of actions and prosecutions (EPA 2009). Smaller enforcement activities, like the control of the collection and movement of waste in the local authority's jurisdiction and the regulation of smallscale waste activities that do not require a licence from the EPA, are carried out by the environmental departments of local authorities.

Previous studies carried out in the area of environmental legislation have demonstrated that some aspects of waste enforcement are related to geographical features of the area under interest. As an example, certain geographical features may influence the likelihood of illegal dumping in the area (Tasaki et al. 2007). In other cases, the type of waste management policies implemented by the local government in an area can crucially influence the attitudes of the population towards household waste management practices (Davies et al. 2006). In the Republic of Ireland, there are currently 34 local authorities which oversee environmental enforcement, including 29 county councils and five citylevel entities. These authorities are very geographically varied. The four local authorities within the Dublin county area (Fingal County Council, Dublin City County Council, Dublin South County Council and Dún Laoghaire-Rathdown County Council) are highly populated, whereas counties such as Leitrim have a low population. There are also contrasts between coastal counties, like Mayo and Kerry, and the midlands counties of Longford or Monaghan, and between more mountainous territories like Wicklow and Galway, and those like Westmeath and Cavan which have numerous lakes and rivers. These variations have implications for waste enforcement.

A survey was conducted among the environment departments of the 34 Irish local authorities in 2012 in order to assess the current environmental waste enforcement situation in Ireland. The focus was on identifying current waste enforcement issues, where there is non-compliance with environmental policies, faced by the authorities. It also examined other factors such as the technologies employed for waste enforcement and offender identification, the number of offender prosecutions, the cost of environmental enforcement and best practice identification and dissemination.

A participation rate of $50 \%$ was achieved with 17 local authorities completing the survey. The participating local authorities are highlighted in Figure 1. The nonparticipating local authorities were clustered in two main regions: the north-east and east coastal regions, while the north-west coastal region showed an even distribution between participating and non-participating local authorities. For the rest of the regions, a majority of participation was achieved. Despite low participation in some coastal areas, a good representation of local authorities with similar geographical characteristics was obtained from the south-west and south of the country.

The following sections present the data gathered in the different parts of the survey. Information is analysed, discussed and compared with previous studies conducted by other authors. There then follows a general discussion about the survey results and future 
1 - Sligo

2-Galway

3-Clare

4- Limerick

5 -Cork

6 - Cork City

7 - Tipperaty South

8 - Waterford

9 - Fingal

10 - Dublin City

11 - Dublin South

12 - Kildare

13 - Offaly

14 - Laois

15 - Westmeath

16 - Longford

17 - Cavan

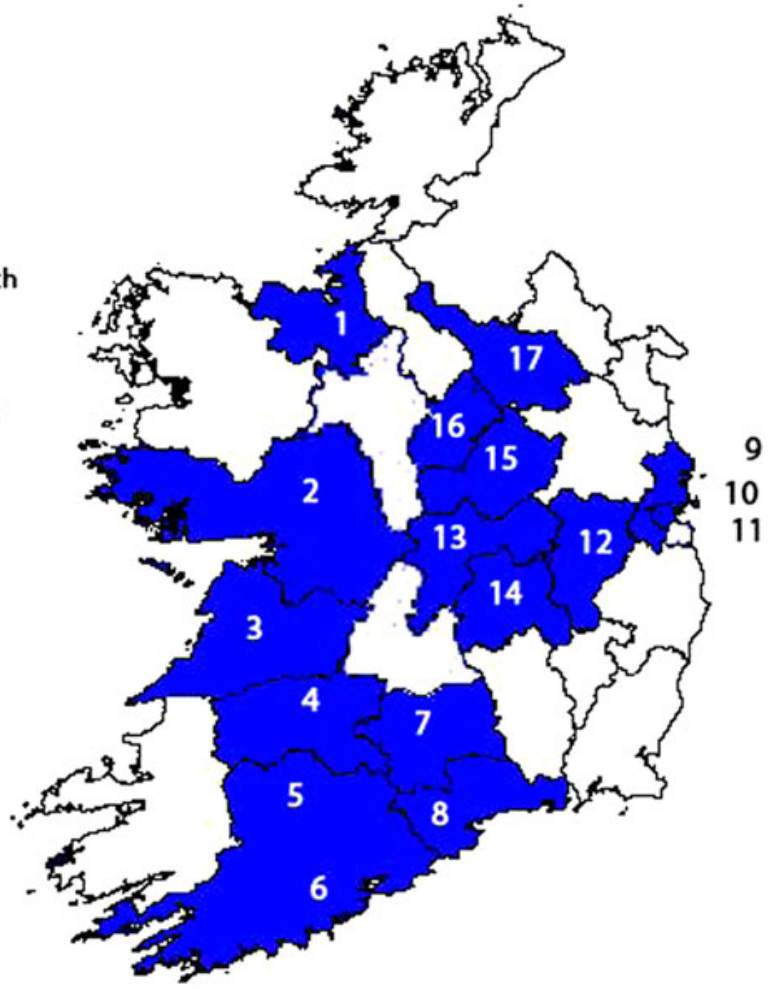

Figure 1. Irish local authorities which participated in the survey study.

actions that could be taken by Irish local authorities to implement more prevention-based environmental enforcement and to reduce the number of offences.

\section{The current local authority waste enforcement situation}

The first part of the survey of Irish local authorities had the objective of gathering information about the current main environmental enforcement issues in their jurisdiction. To fulfil this mission, each local authority was asked to share their top five waste enforcement issues.

The results collected from the participating local authorities are shown in Figure 2. As can be seen, the top issue, identified by more than $80 \%$ of the local authorities, is the illegal dumping of waste, also known as 'fly tipping'. According to the EPA (2005), fly tipping can be described as the indiscriminate dumping of bags containing household waste, waste electronic and electrical equipment, end-of-life vehicles (ELV), pallets, construction and demolition (C\&D) waste and other waste streams. Fly tipping is not a new problem in Ireland. Indeed, the magnitude of this illegal practice has been documented in previous studies where it was highlighted as one of the main waste enforcement issues in the country (Davies et al. 2006, EPA 2009).

The second major issue identified by the survey is the monitoring of authorised or licensed waste facilities, such as landfills. Ireland, as is the case for all EU countries, is obliged to carry out intensive actions in terms of recovery and recycling of waste without 


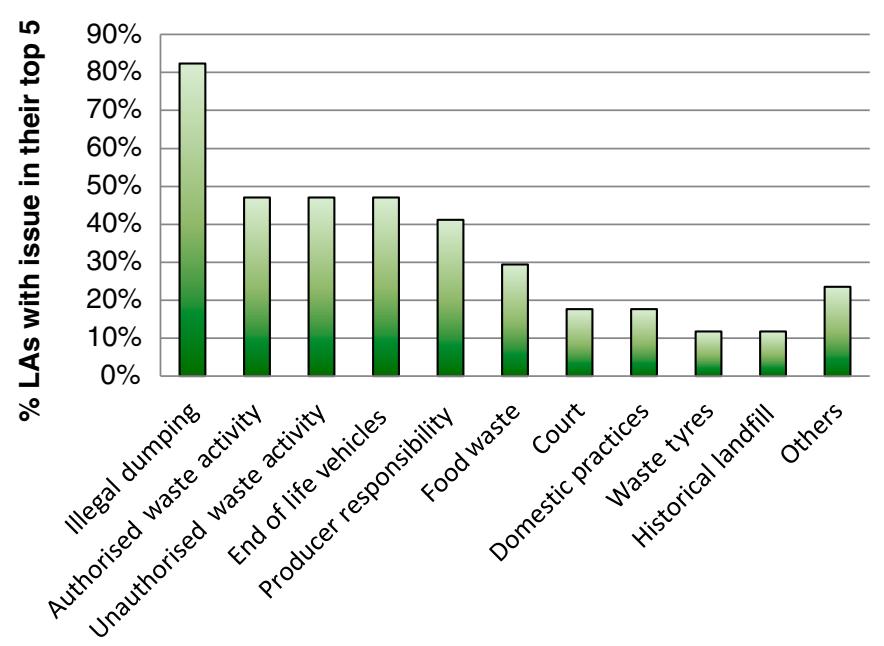

Figure 2. Main environmental issues identified by Irish local authorities.

endangering human health, as well as establishing an integrated and adequate network of disposal installations (EC 2006). While the EPA is directly responsible for reinforcing these directives through inspections of large waste management facilities, such as landfills or waste transfer stations, the local authorities are responsible for carrying out inspections of smaller scale licensed waste activities in their jurisdictions (EPA 2009). These include inspections of the facilities of licensed waste collectors, tyre outlets or vehicle checkpoints. All of these inspections are planned and logged in the Recommendations for Minimum Criteria Environmental Inspections (RMCEI) reports according to the EC's requirements (EC 2001). The RMCEI was adopted by the European Parliament and the EC in 2001 with the purpose of strengthening compliance with, and contributing to more consistent implementation and enforcement of, community environmental law in all EU member states. RMCEI reports are generated by each local authority and submitted to the EPA. While each local authority can view RMCEI reports across all local authorities, the reports are not available to the public. By contrast in the UK, Flycapture is a database of fly tipping incidents reported for each local authority, which also details the number of successful prosecutions by each local authority (Flycapture 2013). A number of aspects which fall into this category are identified individually in Figure 2, due to the frequency with which they were mentioned in survey responses. These include the promotion of producer responsibility for the management of their products when they become waste (EC 2008), separation of organic waste, management of historical landfills and control of waste tyres.

In third place, unauthorised waste activities were captured as an important waste enforcement issue. This category includes unauthorised waste collection, unpermitted waste disposal and waste movement across borders. Unauthorised waste collection has gained more importance in recent years due to the implementation of 'pay-as-you-throw' waste collection schemes (Dunne et al. 2008) and the progressive privatisation of waste collection activities by most Irish local authorities. This privatisation has entailed the termination of waiver schemes in some local authorities such as Fingal County Council (Cotter 2011). Private waste collection now dominates the sector with only Galway City Council, Waterford County Council and Kilkenny Borough Council remaining as public waste collectors (McCoole et al. 2013). 
Finally, ELV were mentioned by many local authorities, mostly because of the strong EU regulations in terms of their dismantling and recycling (EC 2000). The main problems with ELV are twofold: some are illegally abandoned (and sometimes burned) in remote areas, which fall within the illegal dumping category; in other cases, they are processed by unauthorised car dismantlers who do not follow the correct dismantling and recycling procedures, which fall into the unauthorised waste activities category. Other minor issues identified related to the application of environmental law in court and the promotion of environmentally friendly domestic practices.

The surveyed local authorities were asked to share the preventative and reactive practices used in their jurisdictions to address illegal dumping activities and to assess their level of satisfaction with the efficacy of these practices. Preventative methods seek to deter offenders from committing the illegal activity, thereby avoiding it altogether. By contrast, reactive solutions seek to identify and prosecute offenders after an illegal action has been detected.

In general, the local authorities employ preventative practices based on inspections of authorised waste facilities and monitoring of 'hot spots' (defined as locations where illegal dumping takes place on a regular basis) by environmental officers and by closedcircuit television (CCTV) systems. In a preventative way, the environmental officers patrol certain areas, carry out non-routine inspections and perform vehicle check points. A number of local authorities also mentioned preventative measures related to environmental education provided in schools, community centres and through the local authority website. The survey used a 5-level Likert scale to determine the current level of satisfaction with preventative solutions (Likert 1932). The satisfaction scale ranged from ' $1=$ not satisfied' to ' $5=$ totally satisfied'. The average satisfaction level on the Likert scale was 2.43, which indicates dissatisfaction with the preventative solutions employed.

The main reactive solution utilised by the surveyed local authorities was the prosecution of offenders. Actions ranged from on-the-spot fines to court appearances and the confiscation of vehicles involved in illegal dumping activities. In all cases, Irish environmental law, mainly represented by the Waste Management Act (1996) and the Litter Pollution Act (1997), is applied together with the local authority's own by-laws. In addition, CCTV and aerial photography are used to detect illegal activities (such as abandoned ELV) and offenders. Using the same 5-level Likert scale that was used for the preventative solutions (' $1=$ not satisfied' to ' $5=$ totally satisfied'), the average satisfaction level was 2.83 . Although this is an improvement on the result for preventative solutions, it still represents dissatisfaction with the reactive solutions.

The survey found that the CCTV and enforcement officers were the most commonly used resources for both preventative and reactive enforcement actions. A lack of purely preventative measures such as environmental education and awareness was also identified. Previous studies have demonstrated that environmental education plays a crucial role in positive waste management practices, since it creates communication links between the end-users and local authorities (Davies et al. 2006). In addition, when the users are made aware of the real environmental situation of their community and the improvement that positive waste actions can make, they show a greater willingness to adopt positive actions themselves (Barr 2002). However, both studies stress the importance of providing this information by trusted sources and in a manner that is appropriately adapted for the target audience.

The local authorities were asked to specify which of the identified preventative and reactive solutions were considered by them to be best practices, meaning methods or techniques that have consistently shown results superior to those achieved with other 
means. In addition, they were asked to provide details about other national or international best practices of which they were aware. Analysis and comparison of the answers gathered from the local authorities show that for all of them best practices are a synonym for two waste enforcement areas: CCTV or aerial monitoring, and prosecutions. In their answers, none of the local authorities identified environmental education and awareness actions as best practice. This reveals a tendency on the part of local authorities towards reactive measures for environmental enforcement rather than preventative solutions. This same tendency is evident in their awareness of international best practices, where the answers also focused on inspections, CCTV and the creation of a specific, dedicated environmental court for waste enforcement.

Illegal dumping, as the main environmental enforcement issue seen in Figure 2, tends to be carried out in random areas normally away from the public. Previous studies showed that in rural areas, illegal dumping tends to occur in remote areas with difficult access like bogs, forestry areas and commonage. For urban areas, it mainly takes place in recycling centres, normally designated for bottles and clothes collection, and civic amenities (EPA 2005). To complete the overview of current waste enforcement, the local authorities were asked to rank the main areas where illegal dumping takes place in their jurisdiction. To do so, they were provided with a list of possible locations for both urban and rural environments, which they ranked in ascending order with 1 representing the most severe hot spot and 9 the least severe.

The illegal dumping hot spot ranking obtained from the survey is shown in Tables 1 and 2. For urban areas, derelict buildings topped the ranking for illegal hot spots. These are normally areas where the front and backyards (and occasionally the interior) are used for illegal dumping by the offenders, representing health threats for other citizens living nearby. The next ranked urban hot spots were roadside areas and bring banks (or recycling areas). For rural areas, roadside areas were the highest ranked type of hot spot, followed by bogs and forest areas.

The presence of roadside areas at the top of both rural and urban charts highlights its current importance. Of all the area types, this could be considered the one with the most random nature. In general, the waste is transported in private cars and dumped at any point of a road which makes difficult to apply any type of technology for the identification and prosecution of the offenders. Some of the surveyed local authorities carry out random vehicle inspections in an attempt to tackle this practice. However, this is a resource-intensive practice that requires the coordination of the local authority workers with other public bodies such as the police.

Table 1. Ranking of illegal dumping hot spots in urban areas.

\begin{tabular}{ll}
\hline Rank & Urban area hot spot \\
\hline 1 & Derelict areas \\
2 & Roadside \\
3 & Recycling centres \\
4 & Residential \\
5 & Industrial areas \\
6 & Retail areas \\
7 & Parks \\
8 & Beach/coastline/rivers \\
9 & Others (e.g. bus stops) \\
\hline
\end{tabular}


Table 2. Ranking of illegal dumping hot spots in rural areas.

\begin{tabular}{ll}
\hline Rank & Rural area hot spot \\
\hline 1 & Roadside \\
2 & Bogs \\
3 & Forest areas \\
4 & Field gateways \\
5 & Picnic areas/lay-by \\
6 & Quarries \\
7 & Rivers/lakes \\
8 & Beach/coastline \\
9 & Others (e.g. farms) \\
\hline
\end{tabular}

\section{Waste enforcement technology}

Both preventative and reactive solutions for waste enforcement usually involve the application of technology. In the first case, technology is used with informative, educational or deterring purposes in order to prevent the illegal activity from being undertaken. In the second case, technology is used for the identification of illegal actions and offenders in order to carry out a legal prosecution. The Irish legislation on environmental enforcement, principally the Waste Management Act (1996) and the Litter Pollution Act (1996), aligns with the European environmental law in terms of the polluter-pays principle (EC 2004). As an example, most of the offences carried out by householders who dispose of their rubbish illegally would be seen as violations of the Litter Pollution Act, incurring fines of up to $€ 3000$.

In order to establish the current level of technology usage for waste enforcement, local authorities were asked to specify the technology they use and their level of satisfaction with the results. Environmental officers, because of their importance in relation to waste enforcement actions, were also included in the analysis and compared with the other categories of technologies. Figures 3 and 4 show the responses from the local authorities in relation to the technology employed for waste enforcement for rural and urban areas, respectively. In both types of environment, CCTV and enforcement officers are the two main technologies employed. This was expected, since these are the main reactive and preventative measures used by the local authorities, as outlined in the previous section.

Aerial photography, also mentioned as a preventative and reactive solution, appears as the third most employed option. The aerial images are normally taken from a helicopter or from unmanned aerial vehicles (UAVs), such as quadcopters. The use of UAVs in environmental enforcement is increasing due to the wide capabilities and low cost when compared to other options such as satellite imaging (Lega et al. 2012).

Satellite images are rarely used by the local authorities, but where they are employed, the images are obtained from low resolution-free source systems such as Google Maps (Google 2013). This is due to the expense of high resolution, relatively recent satellite images, which does not ensure high chances of success in identification of offences or prosecution of offenders.

Finally, sensors were the technology with the lowest usage for environmental enforcement, with just one local authority claiming to use them in rural areas, specifically in forests and bogs. Sensors are generally employed for sensing different environment parameters such as air or water quality, and noise levels on a constant basis. In addition, 


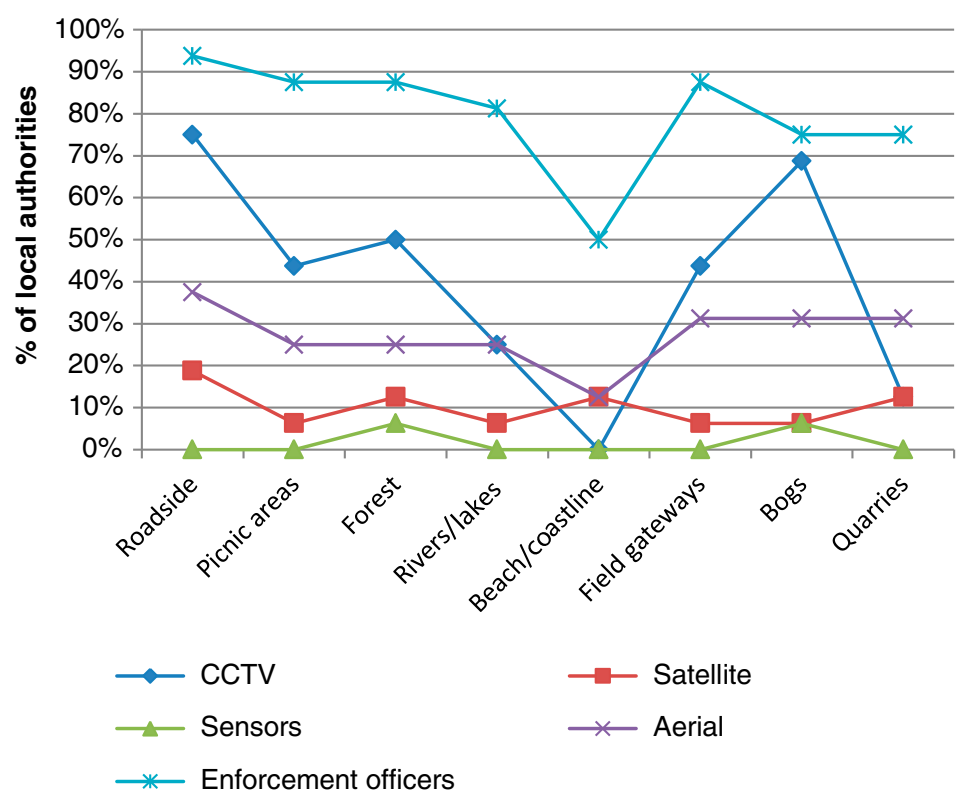

Figure 3. Waste enforcement technology application in rural areas.

they are employed for inspections of premises where emissions to the air or discharges to water are carried out.

The effectiveness of the technologies applied to environmental enforcement can be analysed in terms of the possibility of identification of illegal actions and offenders, as

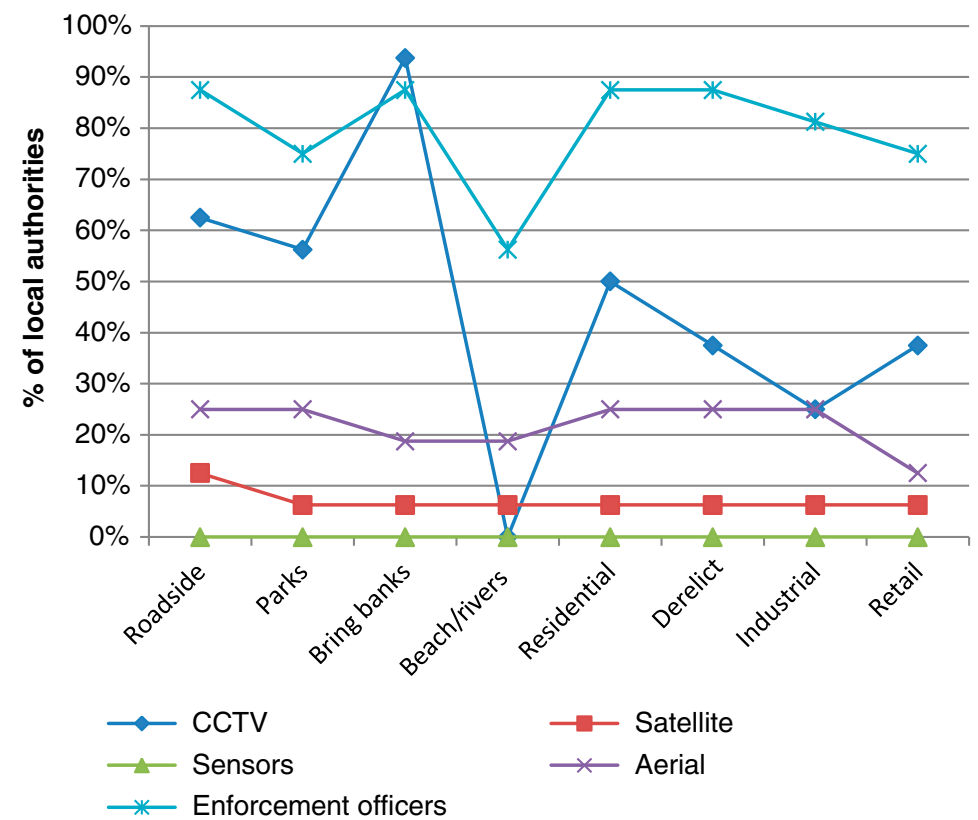

Figure 4. Waste enforcement technology application in urban areas. 
well as the potential to use their outputs to undertake legal prosecution actions against offenders. The local authorities showed a high level of satisfaction with the use of CCTV, environmental officers and aerial imaging, whereas the level of satisfaction with other technologies, such as low resolution satellite imaging, was low.

Overall, the CCTV was considered to be the most successful technology for environmental enforcement. CCTV is less costly in comparison with the sensors or aerial photography taken from helicopters; it provides immediate availability of the images in comparison with outdated image systems such as historical satellite images; and it can be controlled remotely by environmental officers. Most importantly, CCTV systems are the only technology solutions which allow recording of the illegal action while it takes place and not just the consequences of such as action, a point that is crucial in the prosecution process. For example, under the Litter Pollution Act (1997), if the licence registration plate of a vehicle used for an illegal environmental activity is recorded, the owner of the vehicle can be prosecuted as a responsible person.

However, challenging circumstances for the application of CCTV were also reported, such as night-time monitoring, battery-powered CCTV systems for temporal deployment or monitoring remote areas, and CCTV monitoring of high-risk or hostile areas. For these three scenarios, possible solutions based on off-the-shelf commercial CCTV devices were proposed by Palomo et al. (2013).

When the local authorities were asked about the aspect of environmental enforcement technology for which they would most like to see advances, apart from the CCTV improvements described earlier, most referred to the application of information technologies (IT) to enforcement tasks. Some of the ideas proposed were: sharing of databases between agencies, IT tools to assist in inspections, real-time information from waste collectors, waste traceability, database of best practice information and integrated IT applications for environmental officers.

Finally in the area of technology, the local authorities were asked about the utilisation of external contractors for managing the technology deployments and their opinion about new technologies being applied to environmental enforcement. Of the 17 local authorities that completed the survey, the majority $(76 \%)$ employ external contractors to managing some of the technology, whereas $24 \%$ of them do not use contractors.

\section{Offender prosecution}

In Ireland, the environmental departments of the local authorities are the first point of contact for environmental complaints. In 2006 and 2007, the local authorities received about 70,000 environmental complaints about a wide range of environmental issues (EPA 2009). Traditionally, the main environmental complaint channel has been dedicated phone lines provided by the local authorities at a regional level, or by the EPA at a national level with a National Environmental Complaints Line (NECL), initially named 'Dump the Dumpers'. However, with the development of Internet technologies new complaint channels such as online forms and smartphone applications have been made available. According to the EPA (2009), 75\% of the complaints received through the NECL in 2006 and 2007 were in relation to illegal dumping and burning of waste.

The information gathered from the surveyed local authorities showed how the average number of environmental complaints received by each local authority in 2011 was 2082, an increase of $13.9 \%$ from the average of 1828 in 2010. These are received predominantly through phone calls or web-based forms. Some $94 \%$ of local authorities highlighted phone calls directly to the environmental department as the main conduit for 


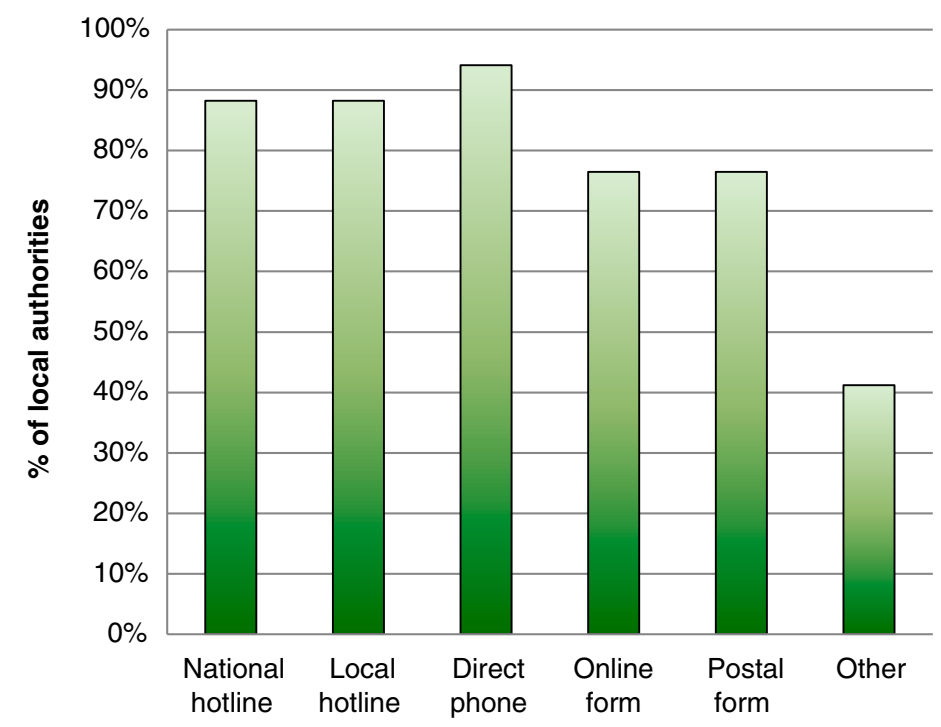

Figure 5. Complaint systems used by local authorities.

complaints, while $88 \%$ of local authorities also received complaints through the EPA national complaints line as shown in Figure 5.

The distribution of complaints received is shown in Figure 6. The majority of complaints received related to waste, in particular litter, averaging at 1520 complaints for each local authority in 2011. The number of litter-related complaints ranged from a high of 5142 for the most reported local authority to a low of just 6 .

The sanctions used in relation to environmental issues can be classified into either administrative or criminal sanctions. Unlike criminal sanctions, administrative sanctions can be imposed directly by the regulator, i.e. local authority, without intervention by a court or tribunal. Such administrative sanctions include information notices, mandatory environmental audits, warning letters, clean-up orders, licence amendments and entry powers (A\&L Goodbody Ltd. and ERM Environmental Consulting 2009). However, for local authorities the administrative sanctions are limited in terms of fines, with the only

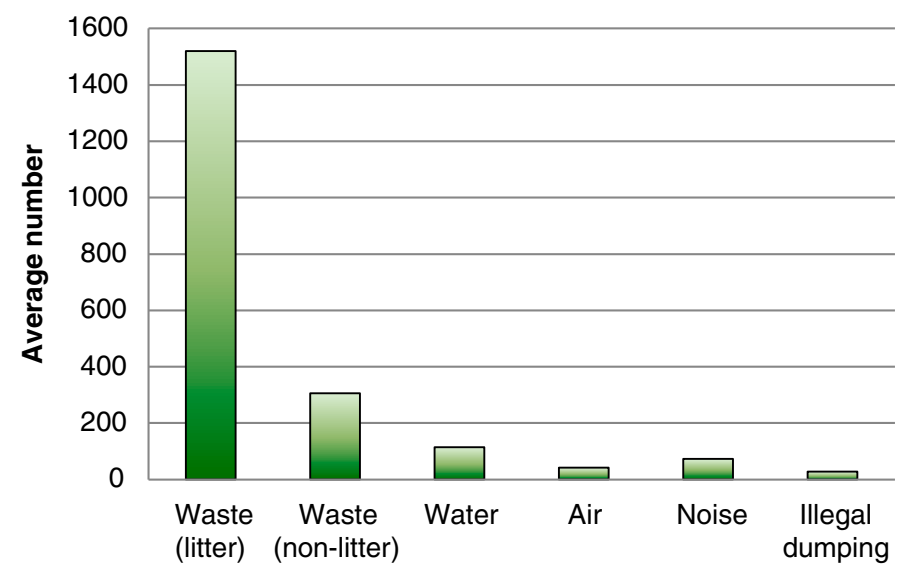

Figure 6. Average number of complaints per local authority for 2011. 
option being a maximum of $€ 150$ penalty for on-spot littering. Higher penalties can be applied under the Litter Pollution and Waste Management Acts following criminal prosecutions.

The importance of the use of warning letters as an administrative sanction in environmental enforcement has been demonstrated by some European countries (Kok 2005). They are considered efficient in cases involving a first offence relating to activities not covered by the key regulations. In Ireland, warning letters are widely used by the regulators like the local authorities, although they do not have any formal statutory basis. In 2007, the Irish local authorities issued 2640 warning letters, whereas 3768 were issued in 2008. If the offence addressed by the warning letter is repeated or persistent, other administrative or criminal sanctions are applied.

Figure 7 shows the average number of warning letters issued and criminal sanctions followed by the surveyed local authorities. The average number of warning letters increased from 119 in 2009 to 162 in 2010 and 155 in 2011. The average number of criminal prosecutions for the years 2009, 2010 and 2011 was 59, 62 and 15, respectively. The drop in the average number of criminal prosecutions in 2011 is very dramatic. The average number of criminal sanctions also dropped from 16 in 2009 to 5 in 2010 and 7 in 2011. Although there was a striking drop in the number of criminal prosecutions in 2011 , the success rate increased remarkably from $7.7 \%$ in 2010 to $45.3 \%$ in 2011 .

From the individual survey results, it can be observed that some local authorities have $100 \%$ success rates in cases they bring to court while others have a $0 \%$ success rate. In order to successfully prosecute an offender, the local authority must have very clear evidence which is collected and presented in a manner that is acceptable to the judge. Local authorities cited the differing interpretation and implementation by judges of the Litter Pollution and Waste Management Acts as the main reason for prosecutions being unsuccessful.

According to the surveyed local authorities, the average cost of bringing a case to court was $€ 2300$ in 2011. The Irish environmental legislation, in particular the Litter Pollution Act (1997), establishes that:

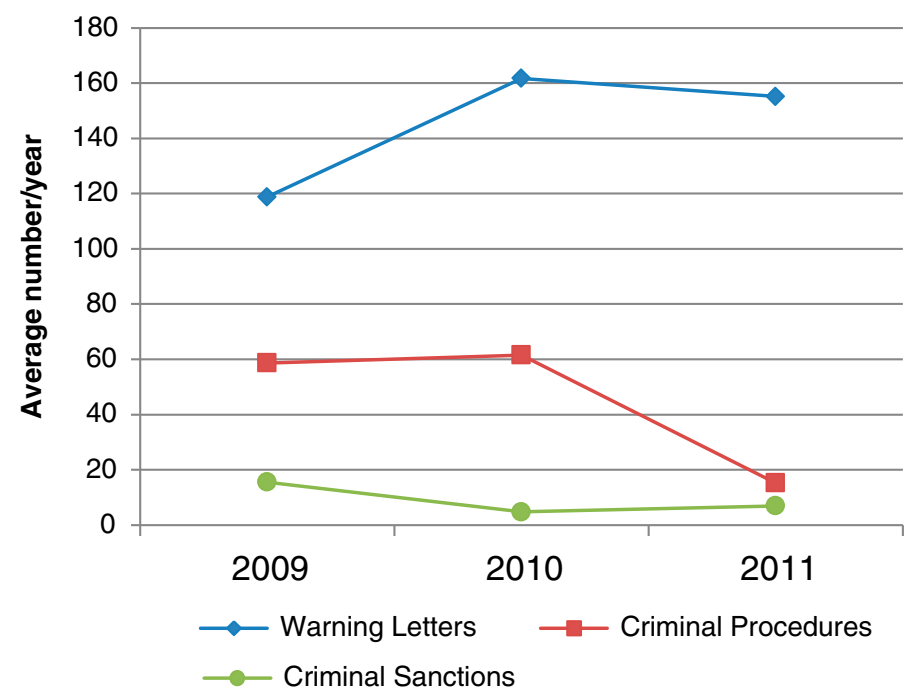

Figure 7. Average number of warning letters, criminal procedures and criminal sanctions per local authority in 2011 . 
when a person is convicted of an offence in proceedings brought by a local authority, the court shall order the person to pay to the local authority the costs and expenses measured by the court, incurred by the local authority in relation to the investigation, detection and prosecution of the offence, and the costs and expenses incurred by the local authority in the collection and disposal of any litter to which the prosecution relates.

Therefore, it is crucial for local authorities to have a high success rate with criminal prosecutions.

When asked about how to improve the prosecution process for environmental offences, all local authorities agreed upon the necessity of the more homogeneous application of environmental law. For example, this might involve the creation of an environmental court with specialised judges who could travel to various regions when environmental cases are being held.

\section{Environmental enforcement cost}

As a consequence of the current economic recession in Ireland, Irish local authorities have suffered budget cuts which affect both the number of staff and the range of services available. For 2011, the average number of full-time staff per local authority dedicated to environmental enforcement was 5.1 employees. As seen in the technology analysis, environmental officers together with CCTV are the two main resources employed for environmental enforcement. In general, local authorities expressed high levels of satisfaction with their enforcement actions, with $71 \%$ of local authorities believing they achieved value for enforcement solutions, whereas $29 \%$ believed they did not. Therefore, a reduction in staff numbers could have a significant impact on environmental enforcement effectiveness.

The results presented in Figure 2 showed that illegal dumping represents the biggest environmental enforcement issue for all Irish local authorities. The clean-up of locations where illegal dumping has taken place represents another significant cost for local authorities. From the survey, it was found that the average cost incurred for cleaning up after illegal dumping was in excess of $€ 118,000$ in 2011 as shown in Figure 8. This represents an $11 \%$ increase over costs for 2009 and 2010.

The previous section highlighted that Ireland does not have administrative sanctions to enable the recovery of clean-up costs from the offender in the case of illegal dumping, unlike other countries such as the UK and Germany (A\&L Goodbody Ltd. and ERM Environmental Consulting 2009). Instead, local authorities can only recover the cost of clean-up if the offender is successfully prosecuted. Considering the low number of successful criminal cases shown in Figure 7, it is remarkable that local authorities have no option other than including the cost of cleaning illegal dump sites in their own budgets, which affects the resources available for other reactive and preventative environmental enforcement actions.

\section{Public awareness and best practice sharing}

According to Davies et al. (2006), Irish homeowners considered illegal dumping and the lack of available landfill to be their most significant waste management issues. However, they felt that there was weak enforcement of waste management policies against illegal dumping. Enhanced transparency, communication and dialogue with the public are decisive actions to avoid illegal waste practices. For example, local waste knowledge has been proven to have a large influence on willingness to recycle (Barr 2002). In addition, 


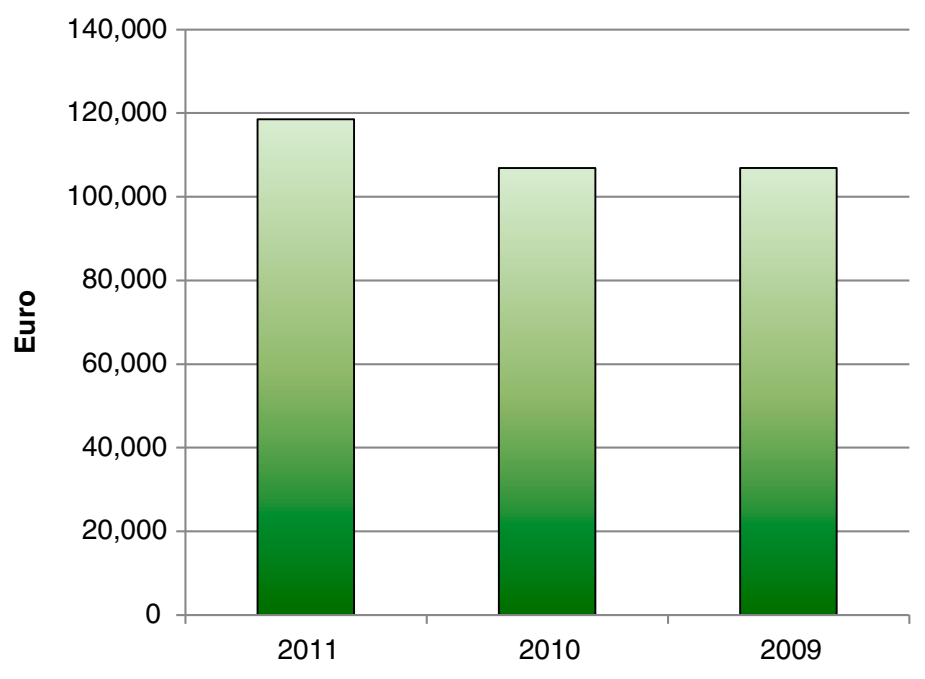

Figure 8. Average local authority annual clean-up spend.

people are more likely to support government policies for environmental protection if they believe that poor environmental conditions are harmful to other people (Stern et al. 1985). This could be applied to the illegal dumping cases in derelict areas which normally attract pests (e.g. rodents) and become a public health risk.

All the surveyed local authorities, with just one exception, indicated that they have a waste enforcement policy document. However, less than half of them confirmed that the document is available on their website, although others confirmed that it was available on request. This poor accessibility can contribute to poor public knowledge regarding environmental law and prosecutable actions.

In a section dedicated to networking and improvement ideas, the surveyed local authorities were asked about the types of public training or awareness programmes on waste enforcement being run in their jurisdiction. Some $76.5 \%$ of the local authorities replied that they do not carry out such training programmes, while $23.5 \%$ replied positively and provided details about the programmes. These are mainly focused on household waste management and food waste management for restaurants. Despite the fact that most local authorities do not carry out any awareness programmes, they are aware of their importance and benefits. For example, one of them recognised that this was the main area requiring improvement as; 'In recent years, it seems that enforcement and awareness have become de-coupled, with not enough focus on proper design of regulations and advice/guidance to the public, communities and businesses who have to comply with the law'.

The other two main points for improvement identified by local authorities were related to the legal side of environmental enforcement, mainly with on-the-spot fines and an environmental court; and the necessity of creating more information-sharing platforms among local authorities. This last point aligns with the suggestions made by the Organisation for Economic Co-operation and Development (OECD) in a review in 2008 where it encouraged the Irish public sector to exploit agility, informality and openness, and to reduce duplication of coordination efforts (OECD 2008).

The exchange of environmental enforcement best practice information has been highlighted in the past as a key factor for all EU member states. Consequently, in 1992 


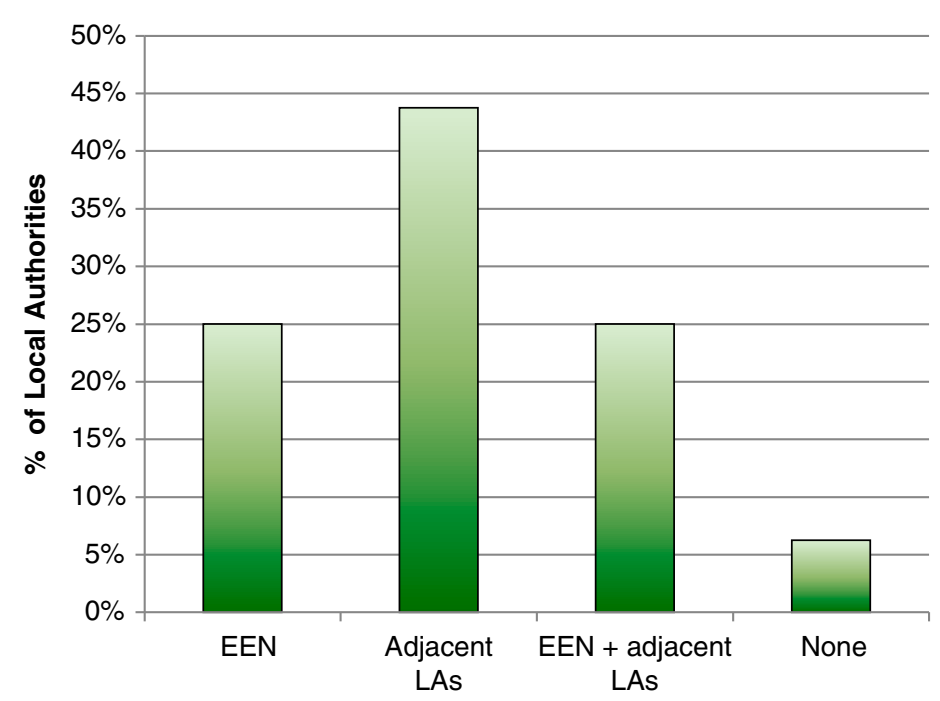

Figure 9. Level of best practice sharing carried out by surveyed local authorities.

the EU Network for the Implementation and Enforcement of Environmental Law (IMPEL) was founded in order to develop common views on the coherence and practicality of legislation, to comment on issues of practicality and enforceability and to develop tools and guidance for use by environmental authorities (Nicholson 2011). Following the success of IMPEL, similar initiatives have been undertaken at a national level among EU member states. In Ireland, the Environmental Enforcement Network (EEN) was created in 2005 with the core objective of 'bringing improved cooperation and coordination between the various agencies involved in enforcement of environmental legislation so that a higher and more consistent standard of environmental protection is achieved in Ireland' (O'Leary and Lynott 2011, p. 757).

The level of environmental enforcement best practice sharing carried out by the surveyed local authorities was analysed. According to Figure 9, 25\% of the local authorities share their best practices with other adjacent local authorities and through the EEN, whereas another $25 \%$ only share it through the EEN, and $44 \%$ only share it with adjacent local authorities. Finally, $6 \%$ of the surveyed local authorities claimed that they do not share any of this information at all.

From the above, it can be seen that half of the surveyed local authorities actually use the EEN for sharing environmental best practices. The local authorities were asked to rank the effectiveness of the EEN on a scale of between 1 and 10, representing 'not effective at all' and 'extremely effective', respectively. The average ranking of 5.5 suggests that, while there is a certain level of satisfaction among the local authorities, there is still room for improvement. The under-resourced management of the EEN and the lack of updated information were the two main areas for improvement pointed out by the surveyed professionals in order to achieve better results.

\section{Discussion}

Despite the continuous improvement in the reduction of solid waste generation and the increasing amount of recycling and separation of organic waste (McCoole et al. 2013), waste-related issues, particularly illegal dumping, are still at the top of Ireland's 
environmental enforcement issues. With the reduction in the amount of C\&D-related waste, most illegal dumping cases are related to the unlawful disposal of household waste. To combat this source of illegal dumping, the Irish Department of the Environment, Community and Local Government is studying future preventative and reactive measures to ensure the correct disposal of household waste. One potential preventative measure is the reintroduction of waiver schemes for low-income households. Such waiver schemes were mostly cancelled with the privatisation of the waste collection services and could have produced a negative impact in the waste disposal of low-income households which may struggle with the pay-by-use schemes adopted by most private collectors (Davies and O'Callaghan-Platt 2008). From the reactive point of view, householders will have to demonstrate that they avail of an authorised waste collection service or that they manage their waste in an environmentally acceptable way (DECLG 2012). A third proposed measure involves an increase in the number of awareness and education campaigns for households (DECLG 2012). Previous studies have shown that Irish householders' knowledge about waste enforcement and waste management policies by local authorities is weak (Davies et al. 2006). This view has been reinforced by this study, which shows the limited number of local authorities carrying out waste enforcement awareness campaigns and the poor availability of their waste enforcement policies to the general public.

Information has been proven to be a key factor in adopting a recycling behaviour, where recyclers generally have more sources of information than non-recyclers (Vining and Ebreo 1990). Similarly, more efforts should be made by the local authorities to make the information about environmental law and enforcement easily available to householders in the right social context at the community level. The successful implementation of these measures would not only lead to the reduction of illegal dumping, but also to the reduction of other unauthorised waste activities (e.g. unauthorised waste collection). The reduction of illegal dumping and unauthorised activities through positive and constructive information campaigns would also reduce the amount of investment required by local authorities on reactive technologies, which have limited applications and generally do not provide a good solution to some of the main problems, such as illegal roadside dumping (Palomo et al. 2013). By saving money in reactive technologies, more could be invested in preventative technologies focused on educating the public in an easy and, in some cases, funny way. Some of these initiatives have proved effective in quickly changing public behaviour (Volkswagen 2013).

In summary, increasing public environmental enforcement education could help improve the following points:

- Reduce the number of criminal prosecutions, therefore reducing associated costs.

- Reduce expenditure on reactive technologies.

- Create longer-term and constructive solutions.

- Create a feeling of fairness and community collaboration.

- Adopt, customise and improve international best practices.

Other waste issues such as the control of authorised waste collectors or authorised ELV dismantlers would continue to be based on constant monitoring and inspections. However, a more active role of all local authorities in terms of sharing best practices through the EEN with regard to legislation, inspection and prosecution could lead to more efficient and unified procedures. This best practice unification is likely to benefit from future plans to reducing the number of waste regions (clusters of adjacent local authorities 
which share a common waste management plan) in Ireland from 10 to no more than 3 (DECLG 2012). Such a reduction in the number of waste regions would favour the concentration of resources and the communication between larger numbers of local authorities, promoting common best practices in the new waste regions.

For criminal prosecutions, environmental law needs to be applied consistently for an offence regardless of jurisdiction. Two possible approaches to achieve this could be the introduction of a wider range of administrative sanctions (A\&L Goodbody Ltd. and ERM Environmental Consulting 2009), which would give more power to the local authorities; and the creation of an association of judges who are specialised in the area of environmental enforcement.

For the first option, administrative sanctions such as fixed penalties, variable and discretionary penalties, or compensation orders, could be introduced in order to avoid highly demanding criminal procedures in many cases. These criminal procedures are often considered to be inappropriate and heavy-handed by the public and judges where the harm caused is not really 'criminal' (A\&L Goodbody Ltd. and ERM Environmental Consulting 2009). In addition, administrative sanctions have been found to be as effective as criminal sanctions in countries including the UK and Germany. However, the introduction of these sanctions would require the adaptation of the current legislation and the creation of new processes, such as appeal mechanisms, which would imply an overhead for local authorities.

The second option, of creating an association of specialised judges, would involve the creation of a national equivalent to the EU Forum of Judges for the Environment (EUFJE 2013). This organisation is open to all EU and European Free Trade Association judges and seeks to gather common judicial experience and valuable information for EU institutions in terms of environmental law. A similar institution in Ireland could ensure that Irish judges dealing with environmental enforcement cases would follow common criteria and guidelines. As another alternative, Ireland could follow in the steps of other European countries like the Netherlands in creating specific environmental courts (Kok 2005).

\section{Conclusions}

This research has established a baseline of the current environmental enforcement landscape in Ireland from the perspective of local authorities. As in many other countries, waste-related issues, in particular illegal dumping, top the rank of environmental enforcement actions. Irish local authorities mainly base their enforcement actions on the identification and prosecution of the offenders through warning letters and criminal sanctions. This prosecution process could be further improved by introducing additional types of administrative sanctions which could be applied directly by local authorities.

This investigation has shown the low level of investment by local authorities on preventative solutions to illegal waste activities such as public awareness and education programmes. As in other environmental areas like recycling, the introduction of this type of programme would deliver long-term and constructive solutions while also reducing the cost of prosecutions. In this respect, some of the preventative best practices used by other countries could be adopted and the experiences shared across local authorities using the existing national EEN. 


\section{Acknowledgements}

The authors would like to thank the EPA for their generous support for the research presented in this article through the Strive programme and the research grant 2011-ET-MS-11. They would also like to thank all the Irish local authorities who collaborated in this study by completing the survey. Finally, they would like to thank the anonymous reviewers for the insightful feedback which contributed to improve the quality of this paper.

\section{Funding}

This work was supported by the Environmental Protection Agency [grant number 2011ET-MS-11].

\section{References}

A\&L Goodbody Ltd. and ERM Environmental Consulting, 2009. A study on the use of administrative sanctions for environmental offences in other comparable countries and assessment of their possible use in Ireland. Dublin: Office of Environmental Enforcement. Available from: www.epa.ie/pubs/reports/enforcement/Admin_Sanctions_final.pdf.

Barr, S., 2002. Household waste in social perspective: values, attitudes, situation and behaviour. Aldershot: Ashgate.

Cotter, E., 2011. Fingal to save $€ 7 \mathrm{~m}$ with sale of bin service. Herald, 13 October. Available from: http://www.herald.ie/news/fingal-to-save-7m-with-sale-of-bin-service-27991425.html.

Davies, A.R., 2012. Geography and the matter of waste mobilities. Transactions of the Institute of British Geographers, 37 (2), 191-196.

Davies, A.R. and O'Callaghan-Platt, A., 2008. Does money talk? Waste charging in the republic of Ireland: government, governance and performance. Journal of Environmental Policy \& Planning, 10 (3), 271-287.

Davies, A., et al., 2006. Environmental attitudes and behaviour: values, actions and waste management. Johnstown Castle, Wexford: Environmental Protection Agency.

Department of the Environment, Community and Local Government (DECLG), 2012. A resource opportunity - waste management policy in Ireland. Dublin: Department of the Environment, Community and Local Government.

Dunne, L., Convery, F.J., and Gallagher, L. 2008. An investigation into waste charges in Ireland, with emphasis on public acceptability. Waste Management, 28 (12), 2826-2834.

EC, 2000. Council Directive 2000/53/EC of 18 September 2000 on end-of life vehicles.

EC, 2001. Council Recommendation 2001/331/EC of 4 April 2001 on providing for minimum criteria for environmental inspections in the Member States.

EC, 2004. Council Directive 2004/35/EC of 21 April 2004 on Environmental Liability with Regard to the Prevention and Remedying of Environmental Damage.

EC, 2006. Council Directive 2006/12/EC of 5 of April 2006 on waste.

EC, 2008. Council Directive 2008/98/EC of 19 November 2008 on Waste and Repealing Certain Directives.

EPA, 2005. The nature and extent of unauthorised waste activity in Ireland. Johnstown Castle, Wexford: Author.

EPA, 2009. Focus on environmental enforcement in Ireland - a report for the years 2006-2008. Johnstown Castle, Wexford: Author.

EUFJE, 2013. European Union forum of judges for the environment [online]. Available from: http:// www.eufje.org/ [accessed 10 May 2013].

Flycapture, 2013. UK environment agency national fly-tipping database [online]. UK Environment Agency. Available from: http://www.environment-agency.gov.uk/research/library/data/41333.aspx [accessed 2 August 2013].

Google Inc, 2013. Google maps [online]. Mountain View, CA: Google Inc. Available from: https:// maps.google.com/ [accessed 20 June 2013].

Gregson, N., Metcalfe, A., and Crewe, L., 2007. Identity, mobility, and the throwaway society. Environment and Planning D: Society and Space, 25 (4), 682-700.

Kok, F., 2005. National strategy for environmental legislation enforcement. In: Seventh international conference on environmental compliance and enforcement, 9-15 April 2005, Marrakech, Morocco, 81-87. Washington, DC: INECE. 
Lega, M., et al., 2012. Illegal dumping investigation: a new challenge for forensic environmental engineering. WIT Transactions on Ecology and the Environment, 163, 3-11.

Likert, R., 1932. A technique for the measurement of attitudes. Archives of Psychology, 22 (140), $1-55$.

McCoole, F., et al., 2013. National waste report 2011. Johnstown Castle, Wexford: Environmental Protection Agency.

Nicholson, M., 2011. Networking in Europe: how networking and cooperation have helped respond to environmental compliance and enforcement challenges in IMPEL member countries. In: Ninth international conference on environmental compliance and enforcement, 20-24 June 2011, Whistler, Canada. Washington, DC: INECE, 779-789.

OECD, 2008. Ireland: towards an integrated public sector [online]. Available from: http://per.gov. ie/wp-content/uploads/Ireland_-_Towards_an_Integrated_Public_Service.pdf [accessed 15 July 2013].

O'Leary, G. and Lynott, D., 2011. The effective use of an environmental enforcement network in Ireland. In: Ninth international conference on environmental compliance and enforcement, 20-24 June 2011, Whistler, Canada. Washington, DC: INECE, 756-764.

Palomo, A., et al., 2013. New CCTV approaches for environmental enforcement in Ireland. WIT Transactions on Ecology and the Environment, 179, 705-716.

Stern, P., Dietz, T. and Black, J.S., 1985. Support for environmental protection: the role of moral norms. Population and Environment, 8 (3-4), 204-222.

Tasaki, T., et al., 2007. A GIS-based zoning of illegal dumping potential for efficient surveillance. Waste Management, 27 (2), 256-267.

Vining, J. and Ebreo, A. 1990. What makes a recycler? A comparison of recyclers and nonrecyclers. Environment and Behavior, 22 (1), 55-73.

Volkswagen, 2013. The fun theory [online]. Available from: http://www.thefuntheory.com/ [accessed 8 May 2013]. 